\title{
BECKWITH-WIEDEMANN SYNDROME: A CASE REPORT
}

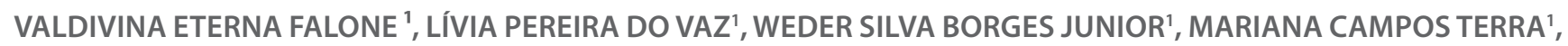 \\ KAMILA DE OLIVEIRA GONÇALVES SOUZA ${ }^{2}$, WALDEMAR NAVES DO AMARAL ${ }^{1}$
}

\begin{abstract}
Beckwith-Wiedemann Syndrome (BWS) is a rare congenital anomaly, with similar manifestation in both sexes and an approximate prevalence of $1 / 13,700$ live births. The main characteristic of this condition is the alteration in the development of certain human organs, which results in growth abnormalities, such as macroglossia, gigantism, hemihyperplasia and visceromegaly, especially in the second half of pregnancy and in the first years of life.

Case report:TVM, female, 26years old. Patient underwent obstetric 4D US with a gestational age of 33 weeks (+/- 7 days). The presence of a projected tongue between the lips was noted, suggesting macroglossia and with a diagnostic hypothesis of Beckwith-Wiedemann Syndrome.

Discussion: In the case reported, a SBW diagnosed with US 4D during the 33rd week of pregnancy was observed. Although not all criteria for BWS could be confirmed in the prenatal examination, the finding of a major sign of possible macroglossia-due to the presence of a projected tongue between the lips - suggested such a diagnostic hypothesis, which was confirmed after delivery.

Conclusion: Through this case, we can observe that imaging tests, such as the US, are of great value, allowing not only to adequately advise the patient, but also to prepare adequate neonatal support at the time of delivery.
\end{abstract}

\section{KEYWORDS: BECKWITH-WIEDEMANN, CONGENITAL ANOMALY, ULTRASOUND}

\section{INTRODUCTION}

Beckwith-Wiedemann Syndrome (BWS) is a rare congenital anomaly, with equal manifestation in males and females and with an approximate prevalence of $1 / 13,700$ live births. ${ }^{1}$ This syndrome alters the pattern of development of certain human organs, especially in the second half of pregnancy and during the first years of life, however adult height is usually normal. In this sense, the growth abnormality is characterized by gigantism, macroglossia and/or hemihyperplasia (can lead to speech and feeding difficulties), visceromegaly, omphalocele and a higher incidence of embryonic tumors. ${ }^{2}$ It is noteworthy that individuals affected by this syndrome may present all or only some of the characteristics mentioned above, therefore BWS is considered as a clinical spectrum.

The etiology of this condition comes from epigenetic and/or complex genetic alterations that misadjust genes on chromosome $11 \mathrm{p} 15.5$, which will be subject to imprinting in the control regions (ICR). The inheritance pattern is of the autosomal dominant type. ${ }^{3}$

The diagnosis of Beckwith-Wiedemann Syndrome can be made in the postnatal period with clinical findings (macroglossia, advanced bone age, omphalocele, neonatal hypoglycemia, visceromegaly, among others). ${ }^{4}$ However, a prenatal diagnosis based on ultrasound scans, via criteria such as macroglossia and estimated weight for such gestational age, is of enormous relevance for the continuity of pregnancy in the perinatal period. ${ }^{5}$ This is because it allows adequate pediatric support for recurrent problems, such as hypoglycemia at birth and embryonic neoplasms. ${ }^{6}$

Next, we will present a case of BWS that was diagnosed in the 33rd gestational week through a "4D" obstetric US.

\section{CASE REPORT}

TVM, female, 26 years old. Patient underwent obstetric 4D US with a gestational age of 33 weeks (+/- 7 days). Upon examination, a fetus of probable female sex was observed in longitudinal situation, cephalic presentation, anterior dorsum and with the presence of rhythmic cardiorespiratory movements (155 bpm). Closed endocervical canal, normal amniotic fluid and umbilical cord with two arteries and one vein inserted normally. Placenta of anterior topical insertion, $25 \mathrm{~mm}$ thick, heterogeneous texture and maturity grade I. A height of $47.3 \mathrm{~cm}$ (growth consistent with gestational age), weight of $2263 \mathrm{~g}(+/-10 \%)$, absence of pre- peritoneal, grade II intestinal staging and other biometric parameters within the appropriate values. Finally, the presence of a pro-
1. Universidade Federal de Goiás

2. IESE Instituto de Ensino em Saúde e Especialização

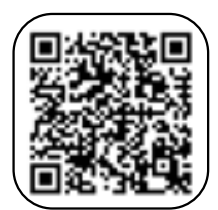

\section{MAILING ADDRESS}

VALDIVINA ETERNA FALONE

Alameda Cel. Joaquim de Bastos, 243 - St. Marista

Goiânia - GO, CEP: 74175-150

Email: valdivinafalone@gmail.com 
jected tongue between the lips was noted, suggesting macroglossia and with a diagnostic hypothesis of Beckwith-Wiedemann Syndrome, which was confirmed after delivery.
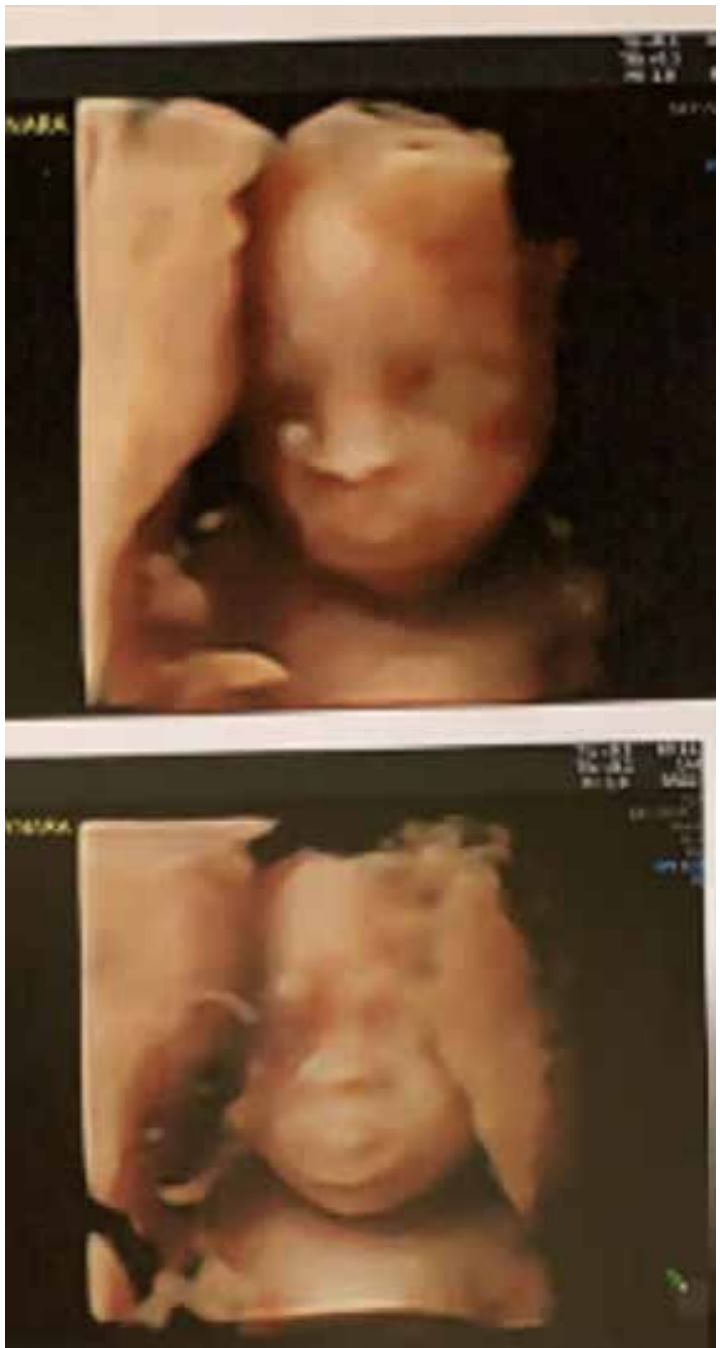

Figures 1 and 2: Macroglossia

\section{DISCUSSION}

In 1963 and 1964, Beckwith and Wiedemann, respectively, reported a syndrome present in newborns, characterized by macroglossia, omphalocele, gigantism, visceromegaly, renal dysplasia, facial nevi, advanced bone age, ear folds and an increase in embryonic neoplasms. ${ }^{7}$ Referred to as one of the main clinical aspects of this syndrome, macroglossia (97\% present) is mostly due to excessive anteroposterior growth of the tongue or muscle hypertrophy, causing its protrusion and, consequently, several possible functional changes in the individual, such as breathing disorders, swallowing, phonation and even psychological consequences. ${ }^{8}$

Although, the diagnosis of BWS is usually performed in the postnatal period through the characteristic clinical find- ings of the condition; the prenatal diagnosis of the condition is still of great value for perinatal continuity, both at birth and in subsequent medical and pediatric care (neonatal hypoglycemia, congestive heart failure, upper airway obstruction and increased risk for neoplasia). ${ }^{4}$ Thus, obstetric ultrasound is used as the standard for detecting major syndromic signs - macrosomia, abdominal wall defect and macroglossia - as well as minor ones - polyhydramnios, nephromegaly, renal dysplasia and adrenal cytomegaly. ${ }^{4}$

In the case reported, a BWS diagnosed with US 4D was observed during the 33rd week of gestation. Although not all criteria for BWS could be confirmed in the prenatal examination, the finding of a major sign of possible macroglossia - due to the presence of a projected tongue between the lips - suggested such a diagnostic hypothesis.
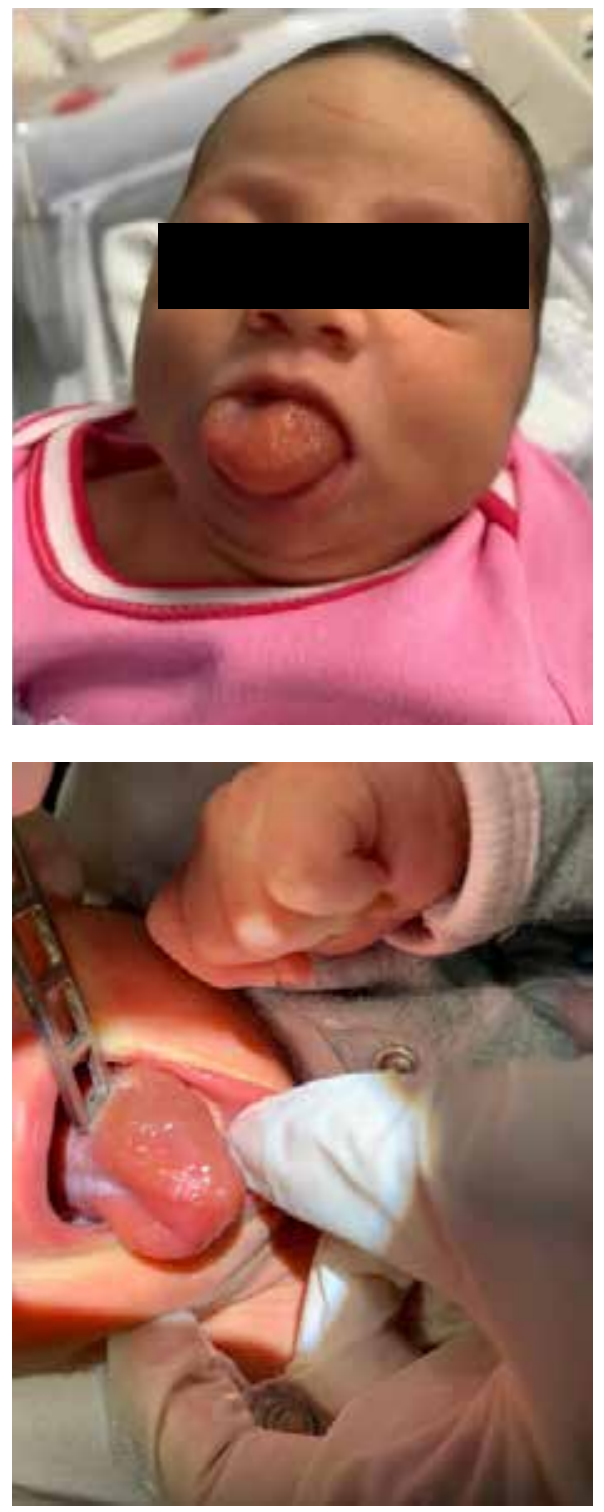

Figures 3 and 4: NB with Macroglossia 


\section{FINAL CONSIDERATIONS}

Thus, we believe, through the case reported, that imaging tests, such as obstetric ultrasonography, are very useful and valuable for the prenatal diagnosis of Beckwith-Wiedemann Syndrome, therefore making possible not only the psychological preparation and understanding of the disease by the parents, but also the adequate training of the multidisciplinary medical team.

\section{REFERENCES}

1. Shuman C, Beckwith JB, Weksberg R. Beckwith-Wiedemann Syndrome.

In: Adam MP, Ardinger HH, Pagon

RA, Wallace SE, Bean LJH, Mirzaa G, Amemiya A, editors. Gene Reviews: University of Washington, Seattle; 1993

2. ABCMED, 2017. Síndrome de Beckwith-Wiedmann. Disponível em:

$<$ https://www.abc.med.br/p/sinais.-sintomas-e-doencas/1301778/sindromede-beckwith-wiedmann.htm >. Acesso em: 5 mai. 2021.

3. Choufani S, Shuman C, Weksberg R. Molecular findings in Beckwith Wiedemann syndrome. Am J Med Genet C Semin Med Genet. 2013; 163C(2):131-140.

4. Araujo Júnior E, Simioni C, Nardozza LM,

Moron AF. Diagnóstico pré-natal da síndrome

de Beckwith-Wiedemann pela ultrassonografia bidimensional e tridimensional. Radiol Bras 2013:46( 6 ): 379-381.

5. Eckmann-Scholz C, Jonat W. 3-D ultrasound imaging of a prenatally diagnosed Beckwith-Wiedemann syndrome. Arch Gynecol Obstet 2011; 284, 1051.

6. Pappas JG. The Clinical course of an overgrowth syndrome, Curr Probl Pediatr Adolesc Health Care. 2015; 45(4): 112-117.

7. Weinstein L, Anderson C. In utero diagnosis of Beckwith-Wiedemann

Syndrome by ultrasound. RSNA Radiology 1980;134(2).

8. Toranzo FJM, Duarte HS, Rodríguez PA. Beckwith-Wiedemann syndrome.

Three case report. Rev ADM. 2001;58(5):170-172. 